\title{
Representações sociais em educação ambiental com estudantes de três cursos da UFCG - Campus de Patos
}

\author{
Angélica Araújo Lima ${ }^{1 *}$, Ivonete Alves Bakke ${ }^{1}$ Alana Candeia de Melo ${ }^{1}$, Leonildo Victor Santos de \\ Lima $^{1}$, Amanda de Lira Freitas ${ }^{1}$, Ana Paula Figueiredo Martins ${ }^{1}$
}

RESUMO: A inferência humana global origina efeitos negativos sobre o meio ambiente à medida que a população e o consumismo crescem descontroladamente. A Constituição Federal Brasileira (1988) estabelece o compromisso do povo em favor do meio ambiente. A Educação Ambiental (EA) orienta e inspira crianças, jovens e trabalhadores a serem críticos e comprometidos. O presente estudo avalia o grau de orientação das Representações Sociais dos alunos de três cursos de graduação na UFCG, Campus de Patos, sendo estes: Engenharia Florestal (EF), Ciências Biológicas (CB) e Medicina Veterinária (MV), sobre os temas e o nível de EA. Foram coletados 150 questionários, 50 de cada curso, com duas questões abertas, para a primeira (Vergés) e para a segunda (Bardin). As categorias mais frequentes foram Preservação EF com nível de EA 94\% regular a ótimo, MV também apontou preservação, e nível de 56\% insatisfatório. CB expressaram a categoria Lixo, e o nível de $64 \%$ com classificação regular a ótimo. A maior frequência de categoria foi a Preservação. A concepção de EA mais preponderante foi a Conservacionista/Resolutiva. Avalia-se como eficiente a formação dos alunos a respeito dos temas ambientais, considerando-se a incorporação de melhorias para o curso de MV, quanto ao emprego da EA.

Palavras-chave: Educação Ambiental, Representações Sociais, estudantes.

\section{Social representations in environmental education with students from three UFCG - Patos Campus}

\begin{abstract}
Global human inference has negative effects on the environment as population and consumerism grow wildly. The Brazilian Federal Constitution (1988) establishes the people's commitment to the environment. Environmental Education (EE) guides and inspires children, youth and workers to be critical and committed. The present study evaluates the degree of orientation of the Social Representations of the students of three undergraduate courses at the UFCG, Campus de Patos. These are: Forest Engineering (FE), Biological Sciences (BS) and Veterinary Medicine (VM) the level of EE. 150 questionnaires were collected, 50 of each course, with two open questions, for the first (Verges) and the second (Bardin). The most frequent categories were EF Preservation with a level of AD 94\% that was regular to optimal, VM also indicated preservation, and a level of 56\% unsatisfactory. BS expressed the Garbage category, and the level of $64 \%$ with regular to optimal classification. The highest frequency category was Preservation. The most preponderant conception of EE was Conservationist / Resolutive. The students' training regarding the environmental themes is evaluated as efficient, considering the incorporation of improvements to the VM course, regarding the use of EE.
\end{abstract}

Keywords: Environmental Education, Social Representations, students.

\section{INTRODUÇÃO}

No Brasil, a Constituição Federal (1988) estabelece no "caput" do artigo 225 que o povo tem como dever a defesa do meio ambiente, por ser de uso comum e direito de todos.

A Lei $\mathrm{N}^{\circ}$ 9.795, de 1999, estabelece a Política Nacional de Educação Ambiental, esta é patrimônio do povo, indispensável para manutenção da vida e da sustentabilidade (BRASIL, 1999).

Resolução $\mathrm{N}^{\circ} 2$ do Conselho Nacional de Educação, de 2012, estabelece as Diretrizes
Curriculares Nacionais (DCN) para a Educação Ambiental (EA) a serem observadas pelos sistemas de ensino e suas instituições de Educação Básica e de Educação Superior, orientando a implementação do determinado pela Constituição Federal (1988) e pela Lei $\mathrm{n}^{\circ} 9.795$ (1999), que determina a implantação da Educação Ambiental em todas as etapas do ensino.

O objetivo do presente estudo é avaliar o grau de orientação acerca das Representações Sociais dos 
alunos de três cursos de graduação existentes na Universidade Federal de Campina Grande (UFCG) do Campus de Patos, sendo estes: Engenharia Florestal (EF), Ciências Biológicas (CB) e Medicina Veterinária (MV), sobre os temas e o nível de Educação Ambiental.

\section{Meio Ambiente e o Homem}

$\mathrm{O}$ despotismo tornou o ser humano indiferente ao fato de que os recursos do meio ambiente além de limitados mantêm também uma inter-relação entre si. Portanto, a redução de um recurso pode ocasionar a diminuição de outro que se relaciona com ele. Contudo, a humanidade constatou que é preciso reverter a situação e reconsiderar o método usado para o desenvolvimento social e econômico (PEDRINI et al., 2002).

O cenário ecológico mundial é complexo diante do cresce aumento da produção alimentícia e a demanda energética desmedida. Faz-se necessário a implantação de um planejamento que objetive a sustentabilidade do meio ambiente (BARBIERI, 1996).

A espécie humana simplesmente repete um histórico cultural de situações de queimas, desmatamento, poluição e desperdício de recursos naturais (BERNA, 2004).

$\mathrm{O}$ padrão ecocêntrico almeja satisfação comunitária pela capacidade regenerativa da terá, no entanto esse modelo tem produzido redução sustentável da vida no mundo. (BAGGIO; BARCELOS, 2008). As principais adversidades são a ineficiência ao usar os recursos e o desperdício no processo de produção (MATOS et al., 2013).

Segundo Moscovici (1975), a sociedade e a natureza não são opostas, ou seja, não é correto imaginá-las como divergentes.

\section{Educação Ambiental}

A Educação Ambiental existe em qualquer âmbito de educação, mantendo valores de justiça e inclusão (BARROS, 2009). Tem por objetivo elucidar problemáticas ambientais em beneficio da vida através do prisma interdisciplinar e cooperação social eficaz (UNESCO, 1977).

A Educação Ambiental colabora com a prática da cidadania, incita atitudes inovadoras, aprimora tecnologias para melhoria ambiental, instigar a modificação comportamental e de valores morais, voltados ao meio ambiente (BERNA, 2004).

Para implantar uma sociedade com práticas sustentáveis são necessárias intervenções em todos os âmbitos, adotando-se ações institucionais, jurídicas, políticas, tecnológicas, científicas e econômicas direcionadas à conservação e recuperação ambiental, outra esfera importante é a educação, fundamental para a construção dessa coletividade (MEC, 2005).

Todas as instituições de ensino superior não devem somente orientar seus alunos a respeito de problemas ambientais, mas também delinear soluções, estimuladas por meio de seus projetos educacionais (OLIVEIRA, 2010).

De acordo com Pedrini et al. (2002), Educação Ambiental envolve o conhecimento produzido pela sociedade, com características multidisciplinares, vocabulário interdisciplinar, e atitudes transdisciplinares. Para estabelecer a Educação Ambiental, discutir fenômenos de forma isolada não é o bastante, é preciso relacionar temas que mantêm interdependência e interdisciplinaridade (GRINGS, 2009).

O Ensino Superior é teoricamente o sustentáculo que estabelece a construção de novas doutrinas para a docência de meio ambiente, no entanto, ainda não tem capacidade de sistematizar um planejamento curricular para buscar o saber que provoque a transformação das atividades didáticas e educativas predominantes que não renunciam ao modo formal que as edificam e mantêm (SILVA, 2013).

$\mathrm{O}$ mercado de trabalho demonstra mudanças devido o avanço científico, tecnológico, político, econômico e social, isso eleva a procura por profissionais competentes e empreendedores, capazes de lidar com os problemas ambientais, com práticas sustentável e ética, assegurando a qualidade de vida e a manutenção do meio ambiente (SILVA; HAETINGER, 2012).

O artigo $2^{\circ}$ da Lei $n^{\circ}$ 9795/99 aponta a Educação Ambiental como constituinte indispensável e constante para a educação da nação, e deve se manter presente, de modo estruturado, em todos os graus e circunstâncias do ensino, formal ou não. $\mathrm{O}$ artigo $4^{\circ}$ da lei especifica os princípios basilares da Educação Ambiental, entre eles se destaca o inciso IV, que determina a incorporação da educação, ética, trabalho e ações dos grupos sociais na prática da Educação Ambiental (BRASIL, 1999).

No que tange ao ensino superior, a legislação indica que a Educação Ambiental deve estar presente no Projeto Pedagógico dos cursos, porém não precisa ser integrada como uma disciplina obrigatória, mas por meio de debates, e práticas de forma interdisciplinar, além do conteúdo teórico, inclusive verificar e desenvolver atividades com o intuito de observar os seus resultados (BRASIL, 1999).

A Agenda 21 Brasileira recomenda que para promover uma capacitação e conscientização que proporcione a sustentabilidade é preciso internalizar questões ambientais no comportamento social por meio da Educação Ambiental, como também habilitar as instituições, visto que a educação é a 
ferramenta fundamental para mudança e a Educação Ambiental é essencial para efetuar a implantação do modelo sustentável (MMA, 2004).

$\mathrm{O}$ artigo $5^{\circ}$ do Decreto $\mathrm{n}^{\circ}$ 4.281/2002 determina que ao incluir a Educação Ambiental nos diversos níveis e modalidades de ensino, deve-se integrá-la às matérias transversalmente, continuamente e permanentemente, e que os docentes devem ter instrução frequente (BRASIL, 2002).

A Resolução no 2/2012 frisa que a Educação Ambiental propõe a construção do conhecimento, o aperfeiçoamento de práticas e ações sociais, o cuidado com a vida, a justiça, o equilíbrio socioambiental e a assistência ao meio ambiente, natural ou edificado (BRASIL, 2012).

Pedrini et al. (2002) orienta que um dos propósitos conectados ao componente socioambiental do ensino superior é a formação do profissional como cidadão com competência para atuar em escolas, empresas e estabelecimentos de pesquisas. E como a universidade é um lugar próprio para o diálogo tem o dever de elaborar uma nova consciência socioambiental.

\section{Representações Sociais}

A teoria das Representações Sociais foi apresentada por Moscovici em 1961, na França, em sua obra La Psychanalyse, son image et son public e, desde então, esse conceito é discutido, preterido, reformulado e muito usado em estudos científicos e averiguações, principalmente no campo dos estudos acadêmicos (GUARESCHI, 1996).

Essa região íntima compõe-se de elementos que, em sua ausência, desarranjariam as representações, transmitindo um significado diferente à sua essência logística (SÁ, 1996). Moscovici (2007) descreve as Representações Sociais partem do princípio que considera a variedade das pessoas, atitudes e fenômenos, com suas extravagâncias e aleatoriedade, esclarecendo a descoberta pelas pessoas e grupos de um mundo equilibrado considerando suas variações.

As características fundamentais ao representar são: a representação de algo que seria um objeto e de alguém que seria um sujeito; simbolismo e interpretação que dá sentido; manifesta-se em forma de saber e qualificação do saber, agindo sobre o mundo e o outro (JODELET, 2001).

A estrutura teórica concentra na origem das Representações Sociais que mesmo simples possui grande amplitude, estruturando de forma simbólica e representativa. E na forma consensual, fica a consideração analítica da dinâmica da familiarização que direciona as representações (SÁ, 1996).

A teoria das RS tem por objetivo visualizar a intenção existente e que às vezes é desconsiderada, bem como a importância de refleti-la, considerando que pode ser essa reflexão a explicação necessária ao entendimento das atitudes das pessoas (GUARESCHI, 1996).

É necessário estarmos orientados constantemente sobre o que ocorre ao nosso redor, isso possibilita uma adequação ao espaço físico e mental, percebendo inconveniências e sanando a problemática que se apresenta (JODELET, 2001).

\section{Representações Sociais e Educação Ambiental}

O ponto de partida para a formação ambiental é o reconhecimento das representações dos envolvidos (REIGOTA, 2007). Todo programa de Educação Ambiental deve considerar primordialmente as Representações Sociais que o meio comprometido com o projeto possui acerca do meio ambiente e sua conexão com este. A conceituação de meio ambiente deve ser aberta e evolutiva, que se desenvolve juntamente com as Representações Sociais e o grupo, não sendo uma questão finalizada (REIGOTA, 2007).

Toda a execução em Educação Ambiental incide diretamente nas representações, reforçando questões positivas ou mudando questões negativas. Esse padrão possibilita um trabalho que identifica a necessidade de mudança ou complemento (TREVISOL, 2004).

A Educação Ambiental empreendedora, preocupa-se com a teoria, mas também detecta, examina e mensura os problemas ambientais, para isso é necessário comprometer-se com os conceitos concomitantemente à prática (RIBEIRO, 2005).

Para aplicar a EA é preciso saber inicialmente como e o que ensinar, pois há amplas alternativas para trabalhar. Por isso é importante conhecer as Representações Sociais dos sujeitos que serão submetidos a esse conteúdo, pois isso possibilitará uma docência dos temas ambientais mais passíveis de ser captada, compreendida e formar indivíduos mais conscientes de suas responsabilidades com o meio ambiente (ARIEIRA, 2013).

\section{MATERIAL E MÉTODOS \\ O Campus}

A pesquisa foi realizada no Centro de Saúde e Tecnologia Rural da Universidade Federal de Campina Grande, situado na cidade de Patos, Paraíba. O Campus foi criado em 1979, denominado Campus VII e pertencia a UFPB (Universidade Federal da Paraíba), funcionava com apenas dois cursos, Medicina Veterinária e Engenharia Florestal. No ano de 2002 houve um desmembramento e foi criada a UFCG e, por consequência, o Campus VII passou a ser denominado Campus de Patos. Atualmente, o Campus apresenta quatro cursos de graduação que são: Medicina Veterinária, Engenharia Florestal, Ciências Biológicas e 
Odontologia. E três cursos de pós-graduação stricto sensu: mestrado em Ciências Florestais e Zootecnia, e mestrado e doutorado em Medicina Veterinária, dessa forma o Campus mantem atualmente um total de 1.385 alunos (PRE, 2015), distribuídos nos cursos de graduação e pós-graduação.

\section{Os Cursos}

A pesquisa foi realizada entre os cursos de Engenharia Florestal, Ciências Biológicas e Medicina Veterinária, pertencentes à UFCG/CSTR, e não incluiu o curso de Odontologia, pois este não dispunha de nenhuma disciplina que abordasse nem de forma transversal a temática de Educação Ambiental.

\section{Engenharia Florestal}

Fundado em 1979, o curso de Engenharia Florestal recebeu seu reconhecimento pelo Conselho Federal de Educação em 1986. Está estruturado em dez períodos letivos e turno diurno, anualmente são abertas quarenta vagas para o curso e os ingressantes são convocados para iniciar no primeiro semestre. Os engenheiros florestais formados pela UFCG são habilitados para proporcionar a administração do patrimônio florestal e a base do desenvolvimento sustentável, a partir de três áreas de atuação: Ecologia Aplicada que viabiliza a harmonia entre o desenvolvimento e a preservação da biodiversidade, Produção Florestal é responsável por todas as atividades alusivas às florestas plantadas e nativas, e Tecnologia de Produtos Florestais que é encarregada pela modificação da madeira em produtos diversos (UAEF, 2016).

Atualmente a Unidade Acadêmica de Engenharia Florestal conta com 150 alunos (PRE, 2015). Como requisito para participar do estudo foi necessário que os alunos tivessem cursado a disciplina Ecologia Geral que é ofertada no segundo período do curso. Portanto, o trabalho foi realizado apenas com alunos a partir do terceiro período, para adquirir uma representação social mais adequada acerca do tema abordado.

\section{Medicina Veterinária}

O curso foi criado em 1979 e reconhecido pelo Ministério da Educação (MEC) em 1985. Composto por dez períodos letivos, funciona em tempo integral (diurno), abre-se cem vagas por ano, cinquenta para o primeiro semestre e cinquenta para o segundo semestre. $\mathrm{O}$ médico veterinário diplomado no Campus de Patos, pela UFCG, tem o dever de atuar em consonância com a preservação da saúde animal e pública, ser capacitado para exercer sua função de acordo com a legislação e de forma humanizada. $\mathrm{O}$ profissional trabalha com nutrição, defesa sanitária, melhoramento animal, clínica e produtos originados por animais, sempre com devido respeito à vida (UAMV, 2016).

A Unidade Acadêmica de Medicina Veterinária tem 408 alunos (PRE, 2015). No entanto, apenas os estudantes a partir do segundo período puderam participar deste trabalho, visto que a disciplina Ecologia é oferecida no primeiro período.

\section{Ciências Biológicas}

O curso foi fundado no ano de 2006, é ofertado em dois turnos, matutino com oito períodos letivos e entrada de quarenta alunos no primeiro semestre do ano, e noturno com dez períodos letivos e ingresso de quarenta alunos no segundo semestre anual. $\mathrm{O}$ licenciado em Ciências Biológicas pela UFCG detém íntimo saber sobre as interações e diversidade dos seres vivos que habitam a biosfera, os níveis de classificação, relações filogenéticas e evolutivas. A formação do processo instrutivo permite o saber biológico, ressaltando seus conceitos, princípios, teorias e o entendimento dessas Ciências em benefício social, educando através de sua vasta atuação profissional, formando cidadãos preparados e conscientes, comprometendo-se na defesa da biodiversidade como herança humana (UACB, 2016).

A Unidade Acadêmica de Ciências Biológicas possui 657 alunos matriculados (PRE, 2015). A disciplina Ecologia Geral é oferecida no quarto período, portanto, os alunos que participaram deste estudo foram aqueles que estavam cursando o quinto período e subsequentes.

\section{Coleta de dados}

Como instrumento para a coleta de dados foi utilizado um questionário (APÊNDICE) aplicado em sala de aula, nas turmas dos cursos de Engenharia Florestal, Medicina Veterinária e Ciências Biológicas, que cursaram a disciplina de Ecologia, pois nenhum dos cursos tem a disciplina de Educação Ambiental como obrigatória na estrutura curricular. Portanto, puderam participar do estudo os alunos do $2^{\circ}$ ao $10^{\circ}$ período de Medicina Veterinária, do $3^{\circ}$ ao $10^{\circ}$ de Engenharia Florestal, do $5^{\circ}$ ao $10^{\circ}$ período de Ciências Biológicas. Para cada curso foram utilizados cinquenta questionários, compondo um total de cento e cinquenta.

O questionário tem duas questões abertas que têm como indução a Educação Ambiental. Na primeira questão os alunos descreveram cinco temas que consideram importantes na Educação Ambiental e que são abordados nos seus respectivos cursos, em seguida ordenaram de acordo com o grau de importância; foram coletadas 250 evocações livres por curso, totalizando 750. A segunda pergunta questiona os estudantes sobre como eles avaliam o nível de abordagem dos temas ambientais no curso. 


\section{Análise de dados}

As Representações Sociais recolhidas foram analisadas de forma coletiva a partir das evocações livres da primeira questão do instrumento de pesquisa foi estabelecida a técnica de estudo de Representações Sociais dos alunos de todos os cursos associadas ao estudo de EA. Na segunda questão, o estudo foi analisado por curso.

$\mathrm{Na}$ primeira questão foi realizada a análise das evocações, para todo o público da pesquisa, através de uma adaptação do método de Vergés expresso por Sá (1996) e com base nos trabalhos de Castro (2004) e Teixeira e Algeri (2011), que visam reconhecer o núcleo central das Representações Sociais de Educação Ambiental. Inicialmente foram identificadas todas as palavras evocadas pelos estudantes e, em seguida, foram reduzidas $\mathrm{e}$ organizadas em grupos diferentes conforme a familiaridade de semântica constatada e similaridade de temas, pois em alguns casos os estudantes consideraram termos com significados diferentes como pertencentes ao mesmo conteúdo, por exemplo: preservação e conservação, restauração e regeneração, entre outros que apesar de possuírem definições diferentes, alguns alunos colocaram como um único tema, entre as expressões evidenciadas pelos discentes. A partir dessa qualificação foi calculada a frequência média de evocação por categoria e também calculada de acordo com a ordem dada a cada expressão para identificar as mais importantes na opinião dos universitários.

Após as reduções às categorias foram realizados os cálculos da média da frequência e da média das ordens médias de evocação com o seguinte procedimento, e o auxílio de uma Planilha Eletrônica.

a) Determinação da frequência de cada categoria;

b) Cálculo da média das frequências de todas as categorias;

c) Cálculo do percentual de cada categoria;

d) Cálculo da ordem média de evocação por categoria, de acordo com as ordens definidas pelos alunos;

e) Cálculo da média das ordens médias das categorias.

As categorias foram organizadas em um quadro, com exceção daquelas que apresentaram frequência menor que $0,5 \%$ para a análise dos três cursos, composto por quatro quadrantes, de acordo com a frequência média de evocação, com a frequência e a ordem média de evocação, que permitiu visualizar os elementos mais suscetíveis de pertencer ao núcleo central e os elementos mais periféricos da Representação Social de Educação Ambiental dos participantes da pesquisa.
As cognições estabelecidas no quadrante superior do lado esquerdo (primeiro quadrante) são as mais propensas a assumir o núcleo central, porque elas apresentam a maior frequência de evocação e as ordens médias abaixo da média das ordens médias, isso indica que os termos foram ordenados como mais importantes pelos estudantes. Em seguida foram analisadas as categorias de acordo com as correntes de EA defendidas por Sauvé (2004) e adaptadas por Nero e Frenedozo (2009). Dessa forma foram definidas as cognições que pertencem ao núcleo central, periféricos próximos, periféricos intermediários e periféricos afastados.

A segunda questão foi examinada separadamente, para cada curso, por meio da técnica de análise de conteúdo de Bardin (1979). Este teste é divido em três partes:

a) Pré-análise: nesta fase realiza-se a leitura e estruturação das primeiras ideias que sequenciarão a análise.

b) Exploração do material: é a fase da análise propriamente dita, ou seja, dos procedimentos aplicados no estudo.

c) Tratamento dos resultados, inferência e interpretação: etapa em que ocorrem as intervenções estatísticas que são simples, como frequência e porcentagem, e em seguida, após a obtenção dos resultados são propostas as suas inferências e a interpretação.

Concluídos os procedimentos de análise dos dados, realizou-se a discussão dos resultados para avaliação das Representações Sociais do público alvo da pesquisa.

\section{RESULTADOS E DISCUSSÃO \\ Os três cursos \\ Primeira questão}

O estudo realizado com os dados dos três cursos pela técnica descrita por Sá (1996) uniu as 750 evocações livres compostas por 169 evocações diferentes. A redução foi realizada após avaliar a semântica e a própria indicação de temas semelhantes pelos alunos; esses termos foram limitados a 44 categorias de temas de EA.

Computados os valores das 150 questões, pelo Programa Excel, obteve-se a frequência $(f)$, o percentual (\%) e a ordem média para cada categoria. $\mathrm{Na}$ Tabela 01 verifica-se que o tema mais apresentado foi Preservação, encontrado 83 vezes $(11,06 \%)$ consoante os dados dos cursos de Engenharia Florestal e Medicina Veterinária quando analisados individualmente que também apresentaram esta categoria como mais frequente, no entanto, os de menores frequências foram Ecoturismo (Engenharia Florestal), Implantação de espécies vegetais (Medicina Veterinária), Consumismo (Medicina Veterinária), Agricultura 
familiar (Medicina Veterinária), Parasitologia (Ciências Biológicas) e Agroambientação do campo (Ciências Biológicas) que apareceram uma vez $(0,13 \%)$ e em apenas um dos três cursos.

A ordem média foi variada entre 1(um) para as categorias Fiscalização Ambiental, Biodiversidade e

Tabela 01 - Categorias dos temas de Educação Ambiental com suas respectivas frequências absoluta e relativa, e ordens médias expressas pelos alunos dos três cursos.

\begin{tabular}{|c|c|c|c|c|}
\hline & CATEGORIA DE TEMAS & FREQUÊNCIA $(f)$ & PERCENTUAL (\%) & ORDEM MÉDIA \\
\hline 1 & Preservação & 83 & 11,06 & 3 \\
\hline 2 & Lixo & 73 & 9,73 & 3,01 \\
\hline 3 & Sustentabilidade & 59 & 7,86 & 2,59 \\
\hline 4 & Poluição & 53 & 7,06 & 3,01 \\
\hline 5 & Ecologia & 53 & 7,06 & 2,58 \\
\hline 6 & Recuperação & 46 & 6,13 & 2,67 \\
\hline 7 & Desmatamento & 39 & 5,2 & 2,58 \\
\hline 8 & Educação Ambiental & 38 & 5,06 & 2,89 \\
\hline 9 & Aquecimento Global & 34 & 4,53 & 3,32 \\
\hline 10 & Manejo & 31 & 4,13 & 3,64 \\
\hline 11 & Água & 31 & 4,13 & 2,77 \\
\hline 12 & Política e Legislação & 22 & 2,93 & 3,72 \\
\hline 13 & Sociologia Rural & 22 & 2,93 & 3,54 \\
\hline 14 & Impactos Ambientais & 21 & 2,8 & 2,95 \\
\hline 15 & Clima & 21 & 2,8 & 2,76 \\
\hline 16 & Conforto & 13 & 1,73 & 1,92 \\
\hline 17 & Incêndios & 11 & 1,46 & 3,63 \\
\hline 18 & Conteúdo das Disciplinas & 11 & 1,46 & 3,90 \\
\hline 19 & Criação de animais & 11 & 1,46 & 3,18 \\
\hline 20 & Nutrição animal & 8 & 1,06 & 3,25 \\
\hline 21 & Efeitos antropológicos sobre o meio ambiente & 8 & 1,06 & 3,87 \\
\hline 22 & Uso inadequado & 6 & 0,8 & 3 \\
\hline 23 & Interação entre Homem e Meio Ambiente & 6 & 0,8 & 2,33 \\
\hline 24 & Melhoramento Florestal & 4 & 0,53 & 3,25 \\
\hline 25 & Utilização de Recursos Naturais & 4 & 0,53 & 4,5 \\
\hline 26 & Agrotóxicos & 4 & 0,53 & 3,25 \\
\hline 27 & Saúde & 4 & 0,53 & 3 \\
\hline 28 & Sistemática e Biogeografia & 4 & 0,53 & 2,5 \\
\hline 29 & Meio ambiente e animais & 3 & 0,4 & 3,33 \\
\hline 30 & Alimentação natural & 3 & 0,4 & 4 \\
\hline 31 & Tráfico de animais & 3 & 0,4 & 3 \\
\hline 32 & Evolução & 3 & 0,4 & 3 \\
\hline 33 & Arborização e Paisagismo & 2 & 0,26 & 3,5 \\
\hline 34 & Fiscalização ambiental & 2 & 0,26 & 1 \\
\hline 35 & Maus tratos a animais & 2 & 0,26 & 2,5 \\
\hline 36 & Extinção de espécies & 2 & 0,26 & 5 \\
\hline 37 & Biodiversidade & 2 & 0,26 & 1 \\
\hline 38 & Energia & 2 & 0,26 & 1,5 \\
\hline 39 & Ecoturismo & 1 & 0,13 & 1 \\
\hline 40 & Implantação de espécies vegetais & 1 & 0,13 & 2 \\
\hline 41 & Consumismo & 1 & 0,13 & 4 \\
\hline 42 & Agricultura familiar & 1 & 0,13 & 3 \\
\hline 43 & Parasitologia & 1 & 0,13 & 5 \\
\hline 44 & Agroambientação do campo & 1 & 0,13 & 3 \\
\hline
\end{tabular}

Ecoturismo, e 5 (cinco) para as categorias Parasitologia e Extinção de espécies. Com esses valores calculou-se a frequência média das categorias de temas que foi igual a 17,04 e a média das ordens médias das evocações das categorias igual a 3,01 . 
cursos, para o curso de Medicina Veterinária só houve exceção do tema Conforto e para o curso de Ciências Biológicas a isenção foi Aquecimento Global. As outras categorias estão distribuídas conforme a interseção nos demais quadrantes, com quatro temas no segundo quadrante, seis no terceiro e oito no quarto, estes serão as periferias das Representações Sociais de todos os estudantes que ajudaram na pesquisa.

Quadro 01 - Distribuição das categorias de acordo com a frequência média de evocação (fme) e com a ordem média de evocação (ome) dos três cursos.

\begin{tabular}{|l|l|l|}
\hline \multirow{2}{*}{ FREQUÊNCIA $(\boldsymbol{f})$} & \multicolumn{2}{|c|}{ ORDEM MÉDIA } \\
\cline { 2 - 3 } & INFERIOR A 3,01 & SUPERIOR A 3,01 \\
& Preservação & \\
& Lixo & \\
& Sustentabilidade & \\
IGUAL OU SUPERIOR A & Poluição & Aquecimento Global \\
17,04 & Ecologia & Manejo \\
& Recuperação & Política e Legislação \\
& Desmatamento & Sociologia Rural \\
& Educação Ambiental & \\
& Água & \\
& Impactos Ambientais & \\
& Clima & Incêndios \\
& & Conteúdo das Disciplinas \\
& Conforto & Criação de animais \\
& Uso inadequado & Nutrição animal \\
& Interação entre Homem e Meio & Efeitos antropológicos sobre o meio ambiente \\
& Ambiente & Melhoramento Florestal \\
& Saúde & Utilização de Recursos Naturais \\
& Sistemática e Biogeografia & Agrotóxicos \\
\hline
\end{tabular}

Fonte - Dados da pesquisa

As categorias dos temas propostos na Figura 02 foram classificadas conforme a Figura 01, e auxiliados pelas correntes em Educação Ambiental sugeridas por Sauvé (2004) adaptadas por Nero e Frenedozo (2009). Dessa forma, o núcleo central das Representações Sociais dos alunos dos três cursos, em Educação Ambiental é composto pelas categorias: Preservação, Lixo, Sustentabilidade, Poluição, Ecologia, Recuperação, Desmatamento, Educação Ambiental, Água, Impactos Ambientais e Clima. Estes temas inserem-se nas concepções Conservacionista/Resolutiva,

Eco educação/Sustentabilidade e Naturalista a com predominância para Conservacionista/Resolutiva. Então as representações centrais sugerem uma educação voltada à identificação dos problemas ambientais e soluções, para os preceitos de sustentabilidade, para o aprendizado junto à natureza e experimentação das questões ambientais.

As representações periféricas próximas compreendem a avaliação de quatro temas (Aquecimento Global, Manejo, Política e Legislação, Sociologia Rural) que se caracterizam como concepções das correntes: Moral/Ética, Prática, Humanista e Conservacionista/Resolutiva. Assim estas representações propõem atividades que possam reconhecer e sanar problemáticas ambientais, construir e disseminar para os diversos grupos sociais princípios que resguardem o meio ambiente.
As categorias periféricas intermediárias (Conforto, Uso inadequado, Interação entre Homem e Meio Ambiente, Saúde, Sistemática e Biogeografia) se relacionam com as correntes Conservacionista/Resolutiva, Naturalista, Humanista e Sistêmica. Estas correntes apontam para concepções que destacam a relação da sociedade com a natureza, seja para sobrevivência ou para adquirir conhecimento, bem como reafirma o conceito de uma educação direcionada aos impasses ambientais bem como sua resolutividade.

Os temas Incêndios, Conteúdo das Disciplinas, Criação de animais, Nutrição animal, Efeitos antropológicos sobre o meio ambiente, Melhoramento Florestal, Utilização de Recursos Naturais e Agrotóxicos formam as periferias afastadas e revelam as correntes Conservacionista/Resolutiva, Sistêmica, Naturalista e Humanista. Assim, o conceito conservacionista se mantém como em todo o estudo, ou seja, orientado para os problemas ambientais, seguidos dos fundamentos instrutivos, através da observação da natureza e os transtornos que enfrenta.

A centralidade das Representações Sociais de todos os alunos consultados sobre os temas de Educação Ambiental abordados em seus cursos reafirma o que foi constatado individualmente para cada curso: o conteúdo ensinado nas aulas está mais dirigido para a concepção Conservacionista/Resolutiva, seguida do 
conhecimento da própria natureza e suas problemáticas e do conceito de sustentabilidade. As periferias se classificam pela frequência, ordem média, e em consonância com a proposta de Sá (1996), apresentam o cotidiano da representação e promove uma interação constante que auxilia a compreensão do núcleo. Neste estudo, elas passam por todas as correntes ajustadas por Nero e Frenedozo (2009); isso indica que a prática pedagógica aplicada nos cursos atinge todos os âmbitos da Educação Ambiental.

Figura 02 - Categorias que pertencem ao núcleo central e periferias das Representações Sociais sobre Educação Ambiental dos estudantes dos três cursos.

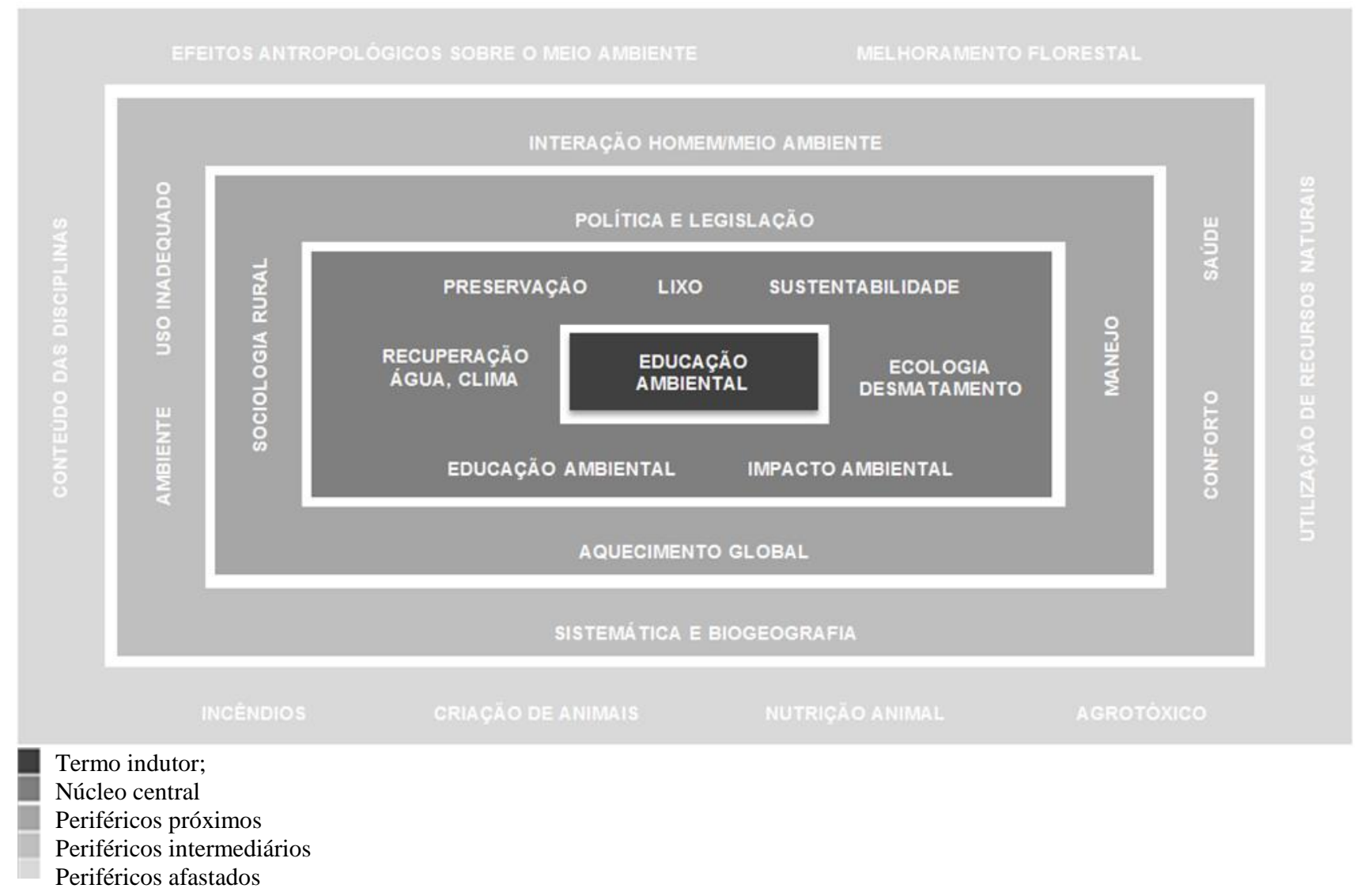

Fonte - Dados da pesquisa.

\section{Segunda questão (Engenharia Florestal)}

A exploração da segunda questão foi elaborada de acordo com a Análise de Conteúdo formulada por Bardin (1979), portanto, a interpretação das respostas dos alunos foi ordenada conforme trechos da argumentação dos mesmos, pois a questão é totalmente subjetiva e deixa espaço para que o discente se expresse de forma livre. Depois de realizar a pré-análise do material foram definidos 16 termos, dentre os que compunham as frases dos alunos para indicar o nível de Educação Ambiental que é abordado no curso de Engenharia Florestal.

A palavra mais utilizada foi Bom que apareceu 11 vezes (22\%) e quanto a menor frequência que foi apenas 1 (uma) vez (2\%) foram representadas por seis termos que foram: bem conduzido, amplamente abordado, mais ou menos, insuficiente, pouco abordado e insatisfatório.
Após exploração do material através de uma releitura e redução das categorias com o auxílio da semântica e podem-se obter seis níveis de abordagem de Educação Ambiental. Em seguida, conforme essas categorias foram efetuadas a análise dos dados que propiciou as frequências das mesmas, exibidas na Tabela 3.

Ao analisar a Tabela 02, pode-se aferir que quase metade dos alunos considera que o nível dos temas ambientais proporcionados no curso de Engenharia Florestal é Bom (48\%), e apenas 6\% dos entrevistados avaliam como insuficiente, os demais qualificam como regular (18\%), muito abordado (16\%), ótimo (6\%) e bom na teoria, mas falta prática (6\%). Esses dados indicam que $94 \%$ dos alunos que participaram da pesquisa classificam o nível de temas ambientais 
Tabela 02 - Distribuição das categorias de nível de Educação Ambiental do curso de Engenharia Florestal de acordo com os alunos.

\begin{tabular}{lcc}
\hline NÍVEL & FREQUÊNCIA $(f)$ & PERCENTUAL $(\%)$ \\
\hline Bom & 24 & 48 \\
Regular & 9 & 18 \\
Muito abordado & 8 & 16 \\
Ótimo & 3 & 6 \\
Bom na teoria, mas falta prática & 3 & 6 \\
Insuficiente & 3 & 6 \\
\hline
\end{tabular}
Fonte - Dados da pesquisa

\section{Segunda questão (Medicina Veterinária)}

Nesta parte do estudo foi utilizado o método de Análise de Conteúdo de Bardin (1979). Inicialmente foram explanadas as argumentações dos estudantes de Medicina Veterinária para a questão que é aberta e permite que eles se expressem como desejarem. Com base na pré-análise do conteúdo 25 termos para identificar o nível dos temas ambientais foram encontrados. Os termos mais frequentes foram Fraco, Pouco explorado e Bom que apareceram quatro vezes $(8 \%)$ e os de menor frequência foram Deficiente, Falta de interesse, Boa relevância, Somente o necessário, Moderado, Muito fraco, Horrível, Deixa muito a desejar, Ótimo e Muito bom, encontradas uma vez cada (2\%). Após exploração do material em que a partir de uma leitura mais atenta e verificando os termos com mesmo significado as categorias foram resumidas a apenas sete níveis de abordagem dos temas ambientais para os quais foi executado o tratamento dos dados para as devidas frequências e porcentagens. Na Tabela 03, é possível inferir que 23 alunos (46\%) veem como Insatisfatório o modo como lhes são apresentados os temas de Educação Ambiental, 10 alunos (20\%) avaliam como Regular, também foram manifestados como Bom (14\%), Ruim (10\%), Bom na teoria, mas falta prática $(6 \%)$, Muito Bom e Ótimo (2\%). Analisando essas informações observou-se que $56 \%$ dos estudantes que auxiliaram a pesquisa avaliam os temas abordados em Medicina Veterinária de forma deficiente, e $44 \%$ consideram proveitoso.

Tabela 03 - Distribuição das categorias de nível de Educação Ambiental do curso de Medicina Veterinária de acordo com os alunos.

\begin{tabular}{lcc} 
Tabela $03-$ Distribuição das categorias de nível de Educação Ambiental do curso de Medicina Veterinária de acordo com os alunos. \\
\hline NíVEL & FREQUENCIA $(\boldsymbol{f})$ & PERCENTUAL $(\%)$ \\
\hline Insatisfatório & 23 & 46 \\
Regular & 10 & 20 \\
Bom & 7 & 14 \\
Ruim & 5 & 10 \\
Bom na teoria, mas falta prática & 3 & 6 \\
Muito bom & 1 & 2 \\
Ótimo & 1 & 2 \\
\hline
\end{tabular}

Fonte - Dados da pesquisa.

\section{Segunda questão (Ciências Biológicas)}

Após a pré-análise do método denominado como Análise de Conteúdo de Bardin (1979) usado para esta segunda questão, foram delimitados 15 termos para indicar o nível de Educação Ambiental inserida no curso de Ciências Biológicas através dos trechos respondidos pelos alunos livremente. Foram obtidos 15 (quinze) termos, em que a palavra mais frequente foi Bom que foi descrito 13 vezes (26\%) e as menos frequentes foram Excelente, Simples, $\mathrm{Na}$ média, Básico, Regular e Razoável com uma presença (2\%).
A exploração do material permitiu rever os termos e reduzi-los a seis níveis, após identificar os termos análogos ou que compreendiam a mesma ideia. O tratamento dos dados exibido na Tabela 04 permitiu definir que 20 (vinte) dos estudantes que participaram da pesquisa (40\%) consideram como Bons os temas ambientais abordados no curso, obtendo a maior frequência, e quanto a menor frequência foi 2 (4\%) para o nível Bom na teoria, mas precisa de prática.

Tabela 04 - Distribuição das categorias de nível de Educação Ambiental do curso de Ciências Biológicas de acordo com os alunos.

\begin{tabular}{lcc}
\hline NÍVEL & FREQUENCIA $(\boldsymbol{f})$ & PERCENTUAL $(\%)$ \\
\hline Bom & 20 & 40 \\
Insatisfatório & 18 & 36 \\
Regular & 4 & 8 \\
Muito bom & 3 & 6 \\
Ótimo & 3 & 4 \\
Bom na teoria, mas precisa de prática & 2 & 6 \\
\hline
\end{tabular}




\section{CONCLUSÃO}

$\mathrm{Na}$ análise do estudo sobre as Representações Sociais com alunos dos três cursos, sobre as temáticas abordadas indicou que a maior frequência de categoria foi a Preservação, e as categorias do núcleo central demonstraram as correntes Conservacionista/Resolutiva, Ecoeducação / Sustentabilidade e Naturalista que, juntamente as representações periféricas, apontaram a presença de todas as correntes de EA. A concepção de Educação Ambiental mais preponderante nos três cursos, analisados individualmente e em grupo foi a Conservacionista/Resolutiva.

Quanto ao nível de EA aplicado no curso de Engenharia Florestal, fica evidenciado que $94 \%$ dos participantes classificaram de regular a ótimo, e 6\% como insuficiente. No curso de Medicina Veterinária mostrou que $44 \%$ dos participantes classificaram de regular a ótimo, e $56 \%$ como sendo insatisfatório. E no curso de Ciências Biológicas apresentou 64\% dos participantes com classificação regular a ótimo, sendo $36 \%$ como insatisfatório.

Dessa forma, com base nas Representações Sociais, podemos dizer que os estudantes estão adquirindo uma formação eficiente a respeito do conteúdo explorado, principalmente voltado para questionar e solucionar problemas ambientais. Porém, aconselha-se que sejam introduzidos recursos pedagógicos apropriados e de forma permanente, de acordo com a legislação vigente, para a Educação Ambiental aplicada no curso de Medicina Veterinária.

\section{REFERÊNCIAS}

ARIEIRA, A. A. S. Representações sociais de educação ambiental para estudantes: jornalismo como estratégia pedagógica. 2013, 85 p. Dissertação (Mestrado em Ensino das Ciências da Saúde e do Meio Ambiente), UniFOA, Volta Redonda - RJ. Disponível em: <http://web.unifoa.edu.br/portal_ensino/mestrado/mecsm a/arquivos/2013/7.pdf>. Acesso em: 05 abr. 2016.

BAGGIO, A.; BARCELOS, A. Educação ambiental e complexidade: entre pensamentos e ações. Santa Cruz do Sul: EDUNISC, 2008.

BARBIERI, E. Desenvolver ou preservar o ambiente? São Paulo, SP: Editora Cidade Nova, 1996.

BARDIN, L. Análise de Conteúdo. Lisboa, Portugal: Edições 70, 1979.

BARROS, M. L. T. Educação ambiental no cotidiano da sala de aula: um percurso pelos anos iniciais. Rio de Janeiro: Ao livro técnico, 2009.
BERNA, V. Como fazer educação ambiental. São Paulo: Editora Paulus, 2004.

BRASIL. Constituição da República Federativa do Brasil. Brasília: Senado Federal, 1988.

BRASIL. Lei $\mathrm{n}^{\circ}$ 9.795, de 27 de abril de 1999. Brasília: Casa Civil da Presidência da República, 1999.

BRASIL. Decreto $\mathbf{N}^{\circ} \mathbf{4 . 2 8 1}$, de 25 de junho de 2002 . Brasília: Casa Civil da Presidência da República, 2002.

BRASIL. Resolução $\mathbf{N}^{\mathbf{2}} \mathbf{2}$ do Conselho Nacional de Educação. Brasília: Ministério da Educação, 2012.

CASTRO, S. M. V. Representação social de ciência de estudantes do ensino fundamental da rede municipal de Belém. 2004, 91 p. Dissertação (Mestrado em Educação em Ciências e Matemáticas), UFPA, Belém PA. Disponível em: <http://www.repositorio.ufpa.br/jspui/bitstream/2011/182 1/1/Dissertacao_RepreRepresentacaoSocialCi.pdf $>$. Acesso em: 07 abr. 2016.

GRINGS, V. T. Educação Ambiental no Ensino Superior: Estudo de Caso no Curso de Agronomia. 2009, 275 p. Tese (Doutorado em Educação), UFRS, Porto Alegre - RS. Disponível em: <http://www.dominiopublico.gov.br/download/texto/cp11 6873.pdf>. Acesso em: 10 abr. 2016.

GUARESCHI, P. Representações sociais: alguns comentários oportunos. Porto Alegre - RS, PUCRS, $1996 . \quad$ Disponível em: <http://www.infocien.org/Interface/Colets/v01n10a003.pd f>. Acesso em: 15 fev. 2016.

JODELET, D. As representações sociais. Trad. Lilian Ulup. Rio de Janeiro: Editora UERJ, 2001.

MATOS, K. S. A. L. et al. Educação Ambiental e Sustentabilidade IV. Fortaleza: Edições UFC, 2013.

MEC. Programa nacional de educação ambiental ProNEA / Ministério do Meio Ambiente, Diretoria de Educação Ambiental; Ministério da Educação. Coordenação Geral de Educação Ambiental. - 3. ed Brasília : Ministério do Meio Ambiente, 2005. Disponível em:

http://portal.mec.gov.br/dmdocuments/publicacao1.pdf $>$. Acesso em: 15 abr. 2016.

MMA. Agenda 21 brasileira. Resultado da consulta nacional / Comissão de Políticas de Desenvolvimento Sustentável e da Agenda 21 Nacional. 2. ed. Brasília : Ministério do Meio Ambiente, 158 p., 2004. Disponível em:

<http://www.mma.gov.br/estruturas/agenda21/_arquivos/ consulta2edicao.pdf $>$. Acesso em: 11 fev. 2016.

MOSCOVICI, S. Sociedade contra natureza. Tradução de Ephraim Ferreira Alves. Petropólis: Editora Vozes, 1975. 
MOSCOVICI, Serge. Representações Sociais: Investigações em Psicologia Social. Trad. Pedrinho A. Guareschi. 6. ed., Petrópolis: Vozes, 2007.

NERO, F. G. D.; FRENEDOZO, R. C. Concepções dos discentes dos cursos de Licenciatura sobre educação ambiental, sua Responsabilidade social e o papel formativo da Universidade. In: VII ENPEC. Resumos. Florianopolis - SC, 2009. Disponível em: <http://www.sbenbio.org.br/wordpress/wp-

content/uploads/2014/11/R0988-1.pdf>.>. Acesso em: 11 abr. 2016.

OLIVEIRA, S. R. P. Reflexões sobre a educação ambiental no ensino superior do estado do Paraná. 2010, 89 p. Dissertação (Mestrado em Geografia), UFOPR, Francisco Beltrão - PR. Disponível em: <http://www.dominiopublico.gov.br/download/texto/cp13 7265.pdf>. Acesso em: 07 abr. 2016.

PEDRINI, A. G. et al. Educação ambiental: reflexões e práticas contemporâneas. Petrópolis: Editora Vozes, 2002.

PRE. Dados UA por período. Patos, PB: UFCG, 2015. Disponível em: <http://pre.ufcg.edu.br:8080/RelatoriosPRE/flow.html/flo wFile/dadosUAPorPeriodo.pdf $>$. Acesso em: 26 fev. 2016.

REIGOTA, M. Meio ambiente e representação social. São Paulo: Editora Cortez, 2007.

RIBEIRO, I. J. L. Educação ambiental e representações sociais: Uma análise transdisciplinar. 2005, 74 p. Dissertação (Mestrado em Ensino das Ciências), UFRP, Recife - PE. Disponível em: < http://www.pge.ufrpe.br/arquivos/teses2003/IJLR.pdf>. Acesso em: 05 abr. 2016.

SÁ, C. P. Núcleo Central das Representações Sociais. Petrópolis, RJ. Editora Vozes, 1996.

SAUVÉ, L. Una cartografía de corrientes en educación ambiental. Université du Québec à Montréal, Montreal, Canadá, 2004. Disponível em: <http://www.ambiente.gov.ar/infotecaea/descargas/sauve 01.pdf>. Acesso em: 08 abr. 2016.

SILVA, A.; HAETINGER, C. Educação ambiental no ensino superior - O Conhecimento a Favor da Qualidade de Vida e da Conscientização Socioambiental. In: Revista Contexto \& Saúde, Ijuí, RS, v. 12, n. 23, p. 34-40, 2012. Disponível em: <https://www.revistas.unijui.edu.br/index.php/contextoes aude/article/viewFile/1832/2538>. Acesso em: 09 fev. 2016.
SILVA, M. L. A educação ambiental no ensino superior brasileiro: do panorama nacional às concepções de alunos (as) de pedagogia na Amazônia. In: REMEA, Rio Grande, RS, v. especial, 2013. Disponível em: $<$ http://www.seer.furg.br/remea/article/view/3438>. Acesso em: 27 nov. 2015.

TEIXEIRA, E. S.; ALGERI, F. L. Representações de meio ambiente e educação Ambiental: um estudo com docentes de casas familiares rurais. In: Práxis Educativa, Ponta Grossa - PR, v.6, n.2, p. 193-205, jul.-dez. 2011. Disponível em: < http://revistas2.uepg.br/index.php/praxiseducativa/article/ viewFile/2440/2315. Acesso em: 03 abr. 2016.

TREVISOL, J. V. Os professores e a educação ambiental: um estudo de representações sociais em docentes das Séries Iniciais do Ensino Fundamental. In: II ENCONTRO DO ANPPAS, 2004, São Paulo - SP: ANPPAS; Papers GT10, p. 27-56, 2004. Disponível em: <http://www.anppas.org.br/encontro_anual/encontro2/ind ex.html>. Acesso em: 11 fev. 2016.

UACB. Perfil do Biólogo. Curso de Graduação em Ciências Biológicas. Patos, PB: UFCG, 2016. Disponível em:

http://www.cstr.ufcg.edu.br/grad_cienc_bio/perfil.htm>.

Acesso em: 02 fev. de 2016.

UAEF. Perfil do Engenheiro Florestal. In: Projeto Pedagógico do Curso de Graduação em Engenharia Florestal. Patos, PB: UFCG, 2016. Disponível em:

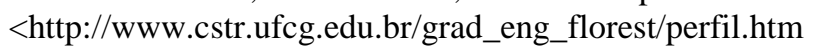
>. Acesso em: 02 fev. de 2016.

UAMV. Perfil do Médico Veterinário. Curso de Graduação em Medicina Veterinária. Patos, PB: UFCG, $2016 . \quad$ Disponível em: <http://www.cstr.ufcg.edu.br/grad_med_vet/perfil.htm>. Acesso em: 02 fev. de 2016.

UNESCO. As grandes orientações da Conferência de Tibilisi. Brasília: Educação Ambiental. Instituto Brasileiro do Meio Ambiente e dos Recursos Naturais Renováveis, $1977 . \quad$ Disponível em:<http://www.fzb.rs.gov.br/upload/20130508155354tbi lisi.pdf>. Acesso em 07 abr. 2016. 